\title{
ИНТЕНСИВНОЕ ОБУЧЕНИЕ РУССКОМУ ЯЗЫКУ КАК ИНОСТРАННОМУ В ФОРМАТЕ ЛЕТНЕЙ ЯЗЫКОВОЙ ШКОЛЫ: ИЗ ОПЫТА РАБОТЫ
}

\section{INTENSIVE TRAINING IN RUSSIAN AS A FOREIGN LANGUAGE IN THE FORMAT OF A SUMMER LANGUAGE SCHOOL: FROM WORK EXPERIENCE}

\section{Dinevich}

Summary: This article is devoted to the organization of intensive training of Russian language as a foreign one in the format of a Summer language school. The principles and methods of working with foreign students are offered according to the course «Intensive Russian language course in RUDN-UNIVERSITY: I speak Russian to the whole world!». The work shows that the main goal of teaching foreign students is formation of the language and speech base, therefore, when implementing the curriculum, the main emphasis to be made on speaking and listening. According to the author, this helps students to carry out successful communication in Russian in various spheres of communication in a language environment.

Keywords: summer language school, intensive Russian language course, the level of language proficiency, language competence, intercultural communication.
B современную эпоху расширения поликультурного образовательного пространства и динамично протекающих глобализационных процессов в области русского языка наблюдается тенденция к расширению международного сотрудничества и увеличению количества совместных научных исследований и проектов ученых из стран ближнего и дальнего зарубежья, посвященных различным аспектам преподавания русского языка как иностранного.

Интерес к изучению русского языка обусловливает открытие языковых школ, курсов, факультетов иностранных языков, что способствует активному продвижению русского языка по всему многоязычному миру. С развитием информационных технологий и доступных средств связи, в первую очередь интернета, мир становится более открытым, поэтому становится возможным проведение вебинаров, онлайн-занятий, изучение русского языка на электронных образовательных платформах.

Особо актуальным и востребованным становится проведение Летних языковых школ для иностранных слушателей, изучающих русский язык как иностранный

\author{
Диневич Ирина Александровна \\ К.филол.н., дочент, ФГАОУ ВО «Российский университет \\ дружбы народов», Москва \\ dinevich_irina@mail.ru
}

Аннотация: Данная статья посвящена рассмотрению организации интенсивного обучения русскому языку как иностранному в формате Летней языковой школы. Предлагаются принципы и методы работы с иностранными учащимися по учебной программе «Интенсивный курс русского языка В RUDN- UNIVERSITY: говорю со всем миром по-русски!». В работе показано, что главная цель обучения иностранных учащихся - формирование языковой и речевой базы, поэтому при реализации учебной программы главный акцент делается на говорении и аудировании. По мнению автора, это помогает слушателям осуществлять успешную коммуникацию на русском языке в различных сферах общения в условиях языковой среды.

Ключевые слова: летняя языковая школа, интенсивный курс русского языка, уровень владения языком, языковая компетенция, межкультурная коммуникация.

в зарубежных школах и вузах и желающих совершенствовать свои умения и навыки владения русской речью в стране изучаемого языка. «Краткосрочные курсы иностранных языков в условиях языковой среды представляют собой идеальную форму практического применения теоретических знаний, полученных учащимися на родине» [Снегурова, 2016, с.1].

Летние языковые школы способствуют продвижению и популяризации русского языка за рубежом среди различных контингентов учащихся образовательных учреждений, формированию у иностранных слушателей языковой и речевой базы, необходимой для успешной коммуникации в условиях языковой среды с использованием определенного набора языковых средств, обеспечивающих возможность адекватного общения в конкретной социальной или этнической группе (в соответствии с их уровнем владения языком), а также расширению мирового образовательного сотрудничества с Российской Федерацией в сфере обучения русскому языку.

Многие ведущие вузы Москвы, Санкт-Петербурга, 
Томска, Екатеринбурга, Калининграда, Самары, Челябинска, Казани и других городов проводят Летние и/или Зимние языковые школы. Обычно учебная программа языковых школ включает в себя интенсивную практику устной и письменной речи, расширение знаний основных грамматических тем, совершенствование навыков говорения и аудирования, корректировку навыков в области практической стилистики, обсуждение актуальных социальных и культурных тем, знакомство с российскими СМИ и работу с текстами разных типов массовой коммуникации, знакомство с культурой и историей России.

Вопросу специфики краткосрочного обучения русскому языку как иностранному в России и за рубежом посвящены многие научные работы, в которых авторы описывают собственный опыт организации и проведения летних языковых курсов [Гончарова, 2015], рассматривают проблемы и перспективы Летней языковой школы [Снегурова, 2016], анализируют «технологию обучения русскому языку как иностранному в языковых школах» [Сизова, 2019].

Факультет русского языка и общеобразовательных дисциплин Российского университета дружбы народов (РУДН) имеет давние и прочные традиции в сотрудничестве с различными образовательными организациями Италии, Франции, Англии, Испании, Венгрии, Чехии, Сирии, Турции, Сирии. В рамках международного сотрудничества факультет ежегодно проводит Летнюю языковую школу по различным образовательным программам, разработанным авторскими коллективами преподавателей факультета.

За последние два года (2018-2019гг.) обучение в Летней языковой школе по программе «Интенсивный курс русского языка в RUDN UNIVERSITY: говорю со всем миром по-русски!» на базе Факультета русского языка и общеобразовательных дисциплин РУДН прошли более 80 человек. Слушателями Летней школы были различные категории обучающихся: слушатели Русской школы дополнительного образования «Антошка» (г. Версаль, Франция), слушатели курсов русского языка частных школ Турции, Ливана, Вьетнама, студенты Русского института Пушкина (г. Мадрид, Испания), Будапештской школы бизнеса (г. Будапешт, Венгрия), Гимназии имени Стояна Велеград (г. Велеград, Чехия), Частного Университета Эль Хаваш (г. Эль Хаваш, Сирия), Миланского университета (г. Милан, Италия).

Программа «Интенсивный курс русского языка в RUDN-UNIVERSITY: говорю со всем миром по-русски!» уникальна, поскольку направлена на решение комплекса учебно-методических задач:

- формирование представления о языковой системе русского языка с учетом уровня владения язы- ком, о правилах функционирования единиц языка в речи и способности пользоваться этой системой для понимания чужих мыслей и выражения собственных суждений в устной и письменной форме;

- развитие и совершенствование практических навыков владения русским языком как иностранным: употребление изученных в рамках определенного уровня грамматических форм, синтаксических конструкций;

- расширение и систематизация словарного запаса учащихся, формирование навыков использования формул речевого этикета при выражении определенных уровнем интенций в рамках заданных тем и ситуаций общения;

- развитие навыков говорения и аудирования (приоритетные виды речевой деятельности), позволяющих сформировать у учащихся представление о языке как отражении социокультурной реальности;

- развитие системных знаний в области коммуникативной грамматики русского языка, формирование умения реализации простых и сложных интенций, выражения оценочной позиции;

- формирование и развитие социокультурной компетенции: знакомство с важнейшими фактами о России, русской культуре, общепринятых правилах речевого и социального поведения;

- развитие навыков межкультурной коммуникации, навыков адекватного взаимопонимания двух участников коммуникативного акта, принадлежащих к разным национальным культурам, навыков вербального и невербального общения;

- формирование интереса иностранных слушателей к русскому языку, литературе и культуре России посредством проведения учебных занятий и экскурсионной программы в рамках Летней школы;

- развитие и укрепление научных, учебных и культурных связей между Российским университетом дружбы народов и зарубежными образовательными организациями.

Сжатость срока обучения (учебный процесс осуществляется в течение 2 недель), высокая концентрация учебных часов (36 часов в неделю), насыщенность учебной программы, полное погружение в языковую среду все это помогает слушателям Летней школы за короткий срок развивать и совершенствовать свои знания по русскому языку и осуществлять коммуникацию в различных сферах общения.

Программа Летней школы «Интенсивный курс русского языка в RUDN-UNIVERSITY: говорю со всем миром по-русски!» включает в себя входное тестирование, ау- 
диторные практические занятия, натурные уроки, написание и представление проекта - творческого эссе по результатам обучения, индивидуальные рекомендации слушателям по дальнейшему изучению русского языка, культурно-экскурсионную программу.

Входное тестирование, проводимое на первом занятии, позволяет разделить слушателей Летней языковой школы разного возраста и разных национальностей на группы в зависимости от уровня владения русским языком: Элементарный уровень (A1), Базовый уровень (A2), Первый сертификационный уровень (B1). Преподаватели Летней школы используют тестовые задания, разработанные Международным центром тестирования РУДН [Балыхина, 2015].

В образованных интернациональных группах обучение ведется без языка-посредника, что способствуют общению обучающихся на русском языке не только на уроках, но и внеаудиторно: во время натурных уроков и культурно-ознакомительных экскурсий. «Такая методика погружения обучающегося в языковую среду повышает внутреннюю мотивацию к усвоению языка и ведет к скорейшей психологической и ментальной адаптации в незнакомой стране, а, следовательно, и к приобретению способности свободно общаться, жить и получать образование в русской социокультурной среде» [Гончарова, 2015, с.21].

Занятия по русскому языку как иностранному проводят высококвалифицированные специалисты, имеющие филологическое образование и обладающие обширными знаниями в области психологии и культурологии, что очень важно при работе в многонациональной аудитории. Аудиторные занятия представляют собой интерактивные практические занятия, предусматривающие аспектное обучение фонетике, лексике и грамматике русского языка. Как правило, каждое занятие включает в себя презентацию и активизацию тематической лексики, необходимый для общения на заданную тему грамматический минимум и отработку речевых образцов в ситуациях межличностного общения. Слушателям предлагаются следующие лексические темы: «Добро пожаловать в Россию», «О культуре, традициях и гостеприимстве», «Природные и климатические особенности России», «Лучше один раз увидеть, чем сто раз услышать», «Знакомство с русской культурой: телевидение, театр, музеи, литература, музыка, живопись», в рамках которых отрабатываются лексический минимум и грамматические конструкции, употребляемые в устной и письменной формах общения.

В соответствии с задачей формирования языковой компетенции обучающихся во время проведения учебных занятий по русскому языку преподаватели ис- пользуют систему лексико-грамматических заданий, развивающих следующие компетенции слушателей Летней школы: когнитивные навыки, познавательную активность учащихся, системные знания в области коммуникативной грамматики русского языка, навыки понимания адаптированных и соответствующих актуальному уровню владения языком аутентичных текстов.

Для развития навыков межкультурной коммуникации используются такие методические приемы, как: использование формул речевого этикета для приветствия, вступления в коммуникацию, привлечения внимания, представления себя и кого-либо, прощания в соответствии с социальными ролями собеседников; инициирования диалога; изменения темы (направления) беседы; завершения темы адекватно ситуации общения. Преподавание основывается на использовании современных инновационных технологий обучения: используются методы активного обучения, работа с неадаптированными материалами (со средствами массовой информации, аудио- и видеосюжетами, с Интернет-ресурсами), интерактивные игры, различные виды дискуссии и обсуждения.

В течение нескольких первых занятий учащиеся Летней школы определяются с выбором темы проекта творческого эссе, предусмотренного в рамках учебной программы: «Я в России», «Национальные особенности русских людей», «Природа и климат России», «Мои впечатления об экскурсии по Золотому кольцу России», «Великий русский писатель / художник / композитор», «Особенности русской культуры». Получив тему проекта, слушатели решают, будет ли это индивидуальное выступление или это будет «работа в тандеме», после чего самостоятельно занимаются сбором материала. При выполнении задания учащиеся из разных стран общаются друг с другом, с преподавателями и студентами Факультета русского языка и общеобразовательных дисциплин, таким образом активно погружаясь в иноязычный культурный континуум. Собрав материал, студенты готовят доклады с использованием Power-point и других компьютерных технологий. Проверка выполнения задания проекта осуществляется на последнем занятии в форме презентации, в ходе которой учащиеся не только выступают с подготовленным творческим эссе, но и демонстрируют умения неподготовленной речи при ответах на вопросы аудитории. После выступлений и подведения итогов слушатели Летней школы получают Сертификат об окончании обучения.

Данные проекты содержат лингвострановедческую и социокультурную информацию и играют важную роль в процессе обучения в Летней школе, поскольку они способствуют развитию умений ориентироваться в коммуникативной ситуации в иной лингвокультурной среде, 
помогают формированию навыков выбора адекватных языковых единиц, а также закреплению нормативных национальных стереотипов.

Для формирования представления о национальнокультурных особенностях социального и речевого поведения носителей русского языка: их обычаев, этикета, социальных стереотипов, истории и культуры страны проводится обширная культурная программа, которая тесно связана с образовательным процессом: выездные учебные занятия (города Золотого кольца России), культурно-ознакомительные экскурсии (обзорная экскурсия по Москве, посещение Красной площади, Кремля, Музеев-заповедников: «Коломенское», «Царицыно», Усадьба Измайлово, Музея космонавтики, Парка Зарядье, Парка Победы, прогулка по Воробьевым горам), натурные уроки (посещение библиотеки, научноисследовательских лабораторий, студенческого кампуса РуДН), видеоклубы русского кино, дискуссионные клубы. Экскурсионная программа тематически раскрывает каждый из аспектов обучения, развивает интерес к русскому языку и русской культуре.

За время обучения в Летней школе слушатели учатся:

- решать определенные коммуникативные задачи в соответствии с нормами русского языка и правилами речевого этикета в рамках обиходно-бытовой, социально-культурной, учебной и официальной сфер общения в рамках ограниченного круга тем и набора интенций;

- воспринимать на слух информацию монологических высказываний и диалогов, основную и дополнительную информацию каждой смысловой части адаптированного звучащего текста;

- самостоятельно продуцировать связные монологические высказывания репродуктивно-продуктивного и репродуктивного характера в рамках заданной темы и коммуникативной установки, а также на базе прочитанного текста социальнокультурного характера;

- выступать инициатором диалога, понимать коммуникативные намерения участников диалогического общения и адекватно реагировать на обращенные реплики, выражая коммуникативные намерения в ограниченном числе ситуаций и тем общения;

- воспринимать основную и дополнительную информацию при чтении специально составленных или адаптированных сюжетных текстов, использовать стратегии изучающего и просмотрового чтения, изменять их в соответствии с установкой;

- строить письменный текст репродуктивно-продуктивного и репродуктивного характера на предложенную тему, а также на основе прочитанного или прослушанного текста в соответствии с заданной установкой;

- преодолевать социальные, этнические и культурные стереотипы, оперировать культурно-специфическими знаниями, которые способствуют взаимопониманию в различных социально-бытовых ситуациях.

По окончании обучения по программе Летней школы «Интенсивный курс русского языка в RUDN-UNIVERSITY: говорю со всем миром по-русски!» слушатели узнают базовые положения основных лексических, грамматических, орфоэпических норм современного русского литературного языка; особенности культуры монологической и диалогической речи; основы грамматической и синтаксической структуры русского языка; основные правила речевого поведения в типичных ситуациях общения в учебной, социально-бытовой и социально-культурной сферах; основные понятия русской культуры.

Комплекс учебных и внеучебных мероприятий в рамках Летней школы требует от всего коллектива преподавателей во главе с руководителем - деканом Факультета русского языка и общеобразовательных дисциплин РУДН, д.п.н., профессором Поморцевой Н.В. тщательной подготовки по всем направлениям. Для успешной реализации главной цели и задач Летней школы со стороны руководителя осуществляется непрерывное координирование работы Летней школы, начиная с подготовительного этапа (оформление приглашений для слушателей, бронирование мест для проживания в гостинице РУДН, разработка учебно-тематического плана занятий, составление экскурсионной программы, организация транспортного сопровождения и питания) и заканчивая контролем проведения учебных занятий преподавателями факультета.

Для преподавателей, работающих в Летней школе, трудным методическим моментом является необходимость строгой дозированности грамматического материала. Ограниченное количество часов, отводимых непосредственно на работу в аудитории, не позволяет презентовать грамматический материал системно и в полном объеме, как это обычно происходит при обучении иностранных студентов на подготовительном факультете. Для изучения выделяются грамматические явления, которые обслуживают определенную коммуникативную тему, и грамматические темы, которые традиционно представляют особую сложность для большинства изучающих русский язык: «Виды глаголов», «Глаголы движения», «Согласование прилагательного с существительным», «Падежи русского языка», «Глагольное управление». Помимо грамматики отрабатываются и другие, актуальные для иностранных учащихся, учебные аспекты: практическая фонетика, фразеология, культу- 
рология.

Необходимо отметить и тот факт, что в учебных группах Летней школы обучаются студенты и слушатели различных образовательных организаций и частных школ, учебные программы которых частично отличаются друг от друга. Кроме того, в группах представлены учащиеся, изучавшие русский язык на родине разное количество времени. Такая гетерогенность учебных групп требует от преподавателя дифференцированного подхода к презентации грамматических тем: одним студентам достаточно комментария преподавателя в ходе урока, другим требуется индивидуальное обучение или дополнительная консультация во внеаудиторное время.

Коммуникативные темы, предлагаемые слушателям Летней школы, носят проблемный характер и отвечают познавательным потребностям и интересам студентов. Иногда учащиеся предлагают свою тематику дискуссий, просят заменить ту или другую тему либо добавить новую. Многообразие и вариативность коммуникативных тем диктуют необходимость гибкого подхода к изучению грамматических явлений. Именно по этой причине преподаватели, работающие в Летней школе, используют различные учебные пособия, которые позволяют студентам углублять свои знания, продолжать самостоятельно изучать русский язык на родине, использовать разделы пособий при подготовке семинаров по различным аспектам русского языка [Беляева, 2013; Дорофеева, 2000; Копытина, 2003; Кривоносов, 2006; Миллер, 2002]. Цель большинства учебных пособий - активизация речевых навыков, помощь в преодолении в сжатые сроки психологического и языкового барьера и выведение в сферу реального повседневного речевого общения [Труфанова, 2002].

Отдельные учебные пособия направлены на отработку лексико-грамматических норм русского языка. Так, например, учебное пособие Н.В. Поморцевой, И.А. Диневич «Глаголы движения» можно использовать при работе как со слушателями, начинающими изучать русский язык, так и с теми, кто владеет русским языком на Первом сертификационном уровне (ТРКИ 1). Таким слушателям, знакомым с особенностями образования и употребления бесприставочных и приставочных глаголов движения, интересно рассмотрение функционирования данных глаголов в пословицах, поговорках и фразеологизмах русского языка, как важной составляющей русской культуры и народной мудрости, для расширения своих знаний по русскому языку и обогащения лингвокультурологического уровня.

Изучение пословиц и поговорок, в которых употребляются глаголы движения без приставок (Волков бояться, в лес не ходить. Тише едешь - дальше будешь. Книгу читаешь - на крыльях летаешь. Любишь кататься - люби и саночки возить) и с различными приставками (Слово не воробей, вылетит - не поймаешь. Annemum приходит во время еды. Жизнь прожить - не поле перейтu) позволяет узнать значение пословиц и поговорок на русском языке и сравнить их со значением на родном языке, что помогает увидеть сходные и отличительные черты двух языковых картин мира и усвоить основные значения глаголов движения русского языка [Поморцева, 2019].

При рассмотрении употребления глаголов движения в переносном значении и во фразеологизмах внимание студентов обращается на то, что от исходного значения глаголов (движение человека в том или ином направлении) образуется значение движения в переносном значении: жизнь идёт; снег идёт; время летит и что парность глаголов однонаправленного и ненаправленного движения утрачивается в переносных значениях. В переносном значении и во фразеологизмах частотно употребление глаголов движения со значением физического и психического состояния человека: прийти в себя - выйти из себя [Поморцева, 2019].

Подводя итоги, можно сказать, что Летняя языковая школа предоставляет уникальную возможность реализовать задачи обучения русскому языку как иностранному в условиях полного погружения в языковую среду с параллельным ознакомлением с жизнью и культурой России.

Проведение Летней языковой школы по программе «Интенсивный курс русского языка в RUDN-UNIVERSITY: говорю со всем миром по-русски!» способствует выполнению целого ряда научных и учебно-методических задач, а именно:

- повышению уровня владения русским языком слушателей Летней школы, их мотивированности в изучении русского языка и формированию творческого потенциала,

- решению актуальных вопросов преподавания русского языка как иностранного и организации дальнейшего обучения русскому языку за рубежом,

- развитию и укреплению научных, учебных и культурных связей между Российским университетом дружбы народов и различными образовательными организациями,

- популяризации и продвижению русского языка за рубежом, а также развитию интернациональной и поликультурной образовательной среды для подготовки элитарных специалистов, конкурентоспособных на международном рынке труда. 


\section{ЛИТЕРАТУРА}

1. Балыхина Т.М. Азбука тестирования (основы российской государственной системы тестирования по русскому языку как иностранному) / Т.М. Балыхина. - Москва: Российский ун-т дружбы народов, 2011. - 30 с.; ISBN 978-5-209-04378-2.

2. Беляева Г.В. Пишем правильно: пособие по письму и письменной речи: начальный этап обучения / Г.В. Беляева, Л.С. Сивенко, Л.В. Шипицо. - Москва: Русский язык. Курсы, 2013. - 324с.; ISBN 978-5-88337-083-9.

3. Гончарова А.В. Летняя языковая школа как организационная форма обучения русскому языку как иностранному / А.В. Гончарова // Наука сегодня: сборник научных трудов по материалам международной научно-практической конференции, г. Вологда, 23 сентября 2015 г.: в 4 частях. Часть 3 - Вологда: 000 «Маркер», 2015. - C.20-22; ISBN 978-5-905713-74-3.

4. Дорофеева Г.М. Учебная грамматика русского языка: Базовый курс: [53 модели] / Т.М. Дорофеева, М.Н. Лебедева. - 2. изд., испр. - Москва: Русский язык. Курсы, 2000. - 279 с.; ISBN 5-88337-005-5.

5. Копытина Г.М. Очень просто! Русский язык для начинающих = Very simple! Russian to beginners / Г.М. Копытина. - 3-е изд. - Москва: Русский язык. Курсы, 2003 (Щербин. тип.). - 105с.; ISBN 5-88337-027-6

6. Кривоносов А.Д. Знаю и люблю русские глаголы: пособие для курсов рус. яз. / А.Д. Кривоносов, Т.Ю. Редькина. - 6-е изд. - Санкт-Петербург: Златоуст, 2006. - 88 c.; ISBN 5-86547-267-4.

7. Миллер Л.В. Жили-были: 28 уроков рус. яз. для начинающих: Учебник / Л.В. Миллер, Л.В. Политова, И.Я. Рыбакова. - 3-е изд., испр. - Санкт-Петербург: Златоуст, 2002. - 152 с.; ISBN 5-86547-254-2.

8. Поморцева Н.В. Глаголы движения: учебное пособие. / Н.В. Поморцева, И.А. Диневич. - Москва: Российский ун-т дружбы народов, 2019. - 98 с; ISBN 978-5-209-09417-3.

9. Сизова Т.В. Технология обучения русскому языку как иностранному в языковых школах / Т.В. Сизова, А.Г. Максимовских. // Педагогические науки. №3 (28), 2018. - C. 86-91. ISSN: 2222-243X

10. Снегурова Т.А. Летняя языковая школа: проблемы и перспективы / Т.А. Снегурова, 0.М. Виктор // Актуальные научные исследования в современном мире. - Харьков: Институт социальной трансформации. - 2016. - № 10-6 (18) . - С. 142-146.

11. Труфанова В.Я. Путь к общению = A way to social interaction : Интенсив. курс речевой адаптации / В.Я. Труфанова. - 3-е изд. - Москва: Русский язык. Курсы, 2002. - 140с.; ISBN 5-88337-015-2.

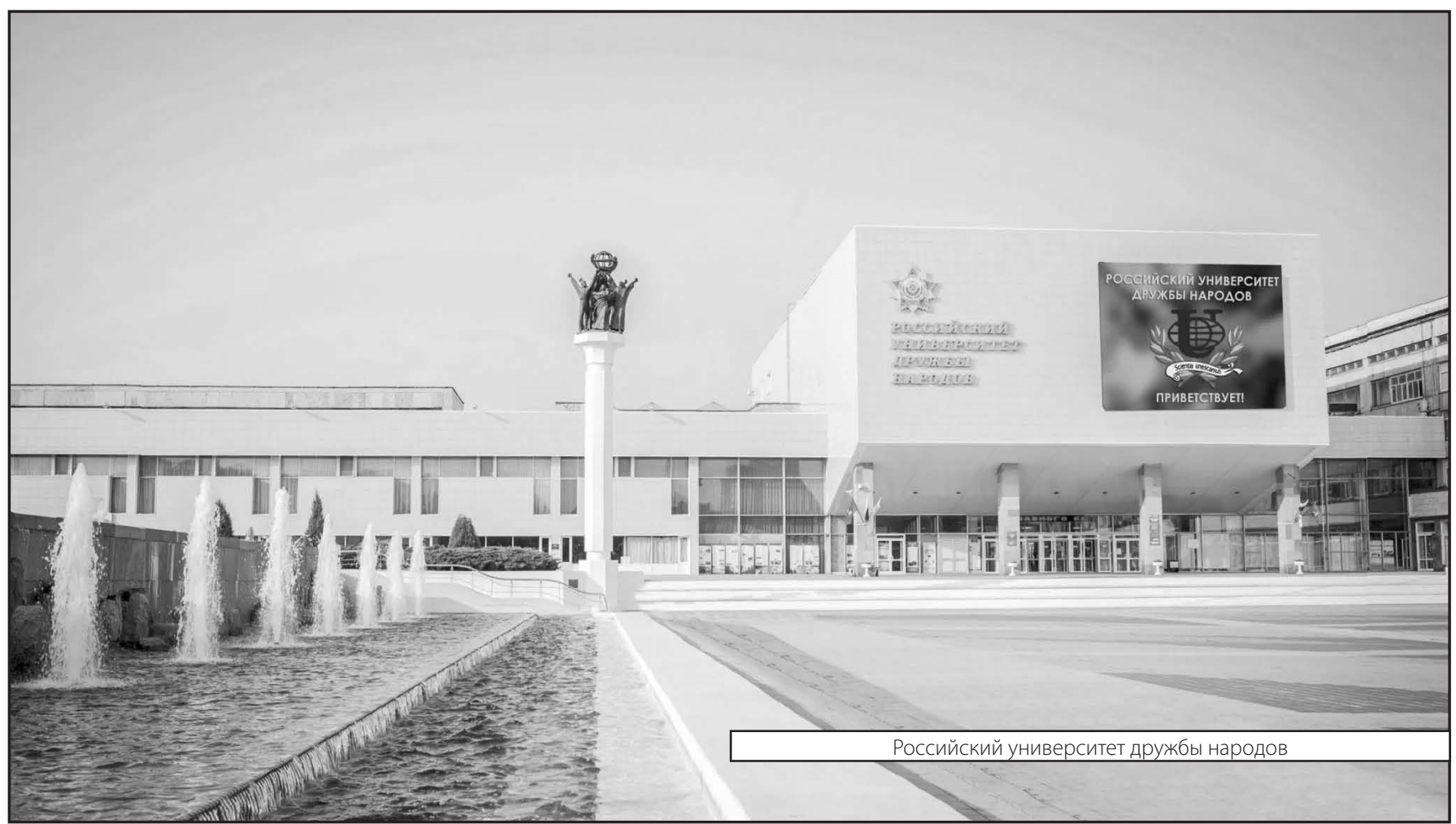

